\title{
Renal oxalosis in free-ranging green turtles Chelonia mydas
}

\author{
Brian A. Stacy ${ }^{1, *}$, Mario Santoro ${ }^{2}$, Juan Alberto Morales ${ }^{2}$, Louis M. Huzella ${ }^{3}$, \\ Victor F. Kalasinsky ${ }^{4}$, Allen Foley ${ }^{5}$, Nancy Mettee ${ }^{6}$, Elliott R. Jacobson ${ }^{1}$ \\ ${ }^{1}$ University of Florida, College of Veterinary Medicine, Small Animal Clinical Sciences, PO Box 100126, Gainesville, \\ Florida 32610, USA \\ ${ }^{2}$ Departamento de Patología, Escuela de Medicina Veterinaria, Universidad Nacional, PO Box 86, Heredia 3000, Costa Rica \\ ${ }^{3}$ Armed Forces Institute of Pathology, Department of Veterinary Pathology, Building 54, Room G-117, \\ 14th Street and Alaska Avenue NW, Washington, DC 20306, USA \\ ${ }^{4}$ Armed Forces Institute of Pathology, Department of Environmental and Infectious Disease Sciences, \\ 14th Street and Alaska Avenue NW, Washington, DC 20306, USA \\ ${ }^{5}$ Florida Fish and Wildlife Conservation Commission, Fish and Wildlife Research Institute, Jacksonville Field Laboratory, \\ 6134 Authority Avenue, Building 200, Jacksonville, Florida 32221, USA \\ ${ }^{6}$ Marinelife Center at Juno Beach, 14200 US Highway One, Juno Beach, Florida 33408, USA
}

\begin{abstract}
Eighteen green turtles Chelonia mydas recovered from the Atlantic and Gulf coasts of Florida and Tortuguero National Park, Costa Rica, were diagnosed with renal oxalosis by histopathological examination. Affected sea turtles included 14 adults and 4 immature animals, which comprised $26 \%$ (18/69) of green turtle necropsy cases available for review. Calcium oxalate deposition ranged from small to moderate amounts and was associated with granuloma formation and destruction of renal tubules. All affected turtles died from traumatic events or health problems unrelated to renal oxalosis; however, 1 immature turtle had notable associated renal injury. Crystal composition was confirmed by infrared and scanning electron microscopy and energy dispersive X-ray analysis. The source of calcium oxalate is unknown and is presumed to be of dietary origin.
\end{abstract}

KEY WORDS: Green sea turtle $\cdot$ Chelonia mydas $\cdot$ Calcium oxalate $\cdot$ Renal oxalosis

\section{INTRODUCTION}

Renal oxalosis in animals is most frequently caused by ethylene glycol intoxication, ingestion of plants containing high levels of soluble oxalate or ingestion of plants contaminated with oxalate-producing fungi. Documented cases in free-ranging wildlife are rare. Toxicosis can either be acute or chronic, and clinical signs result from renal injury and neurovascular oxalate crystal deposition. Low level exposure can be subclinical or have a slow, insidious clinical course as oxalate crystals deposit within the kidneys and cause chronic inflammation.

In this study, we document 18 cases of renal oxalosis in free-ranging green turtles Chelonia mydas from 2 geographical regions, the Florida coast and Tortuguero
National Park (TNP), Costa Rica. Cases were reviewed to characterize the extent of crystal deposition and renal injury, and crystal composition was confirmed by infrared and scanning electron microscopy and energy dispersive X-ray analysis. In addition, available necropsy data and materials from animals recovered from both regions also were reviewed to estimate prevalence of renal oxalosis. To the authors' knowledge, this is the first report of renal oxalosis in marine turtles.

\section{MATERIALS AND METHODS}

Necropsies. Necropsies were performed on stranded green turtles recovered along the Atlantic and Gulf 
coasts of Florida by the Sea Turtle Stranding and Salvage Network and opportunistically on carcasses of nesting female turtles killed by the jaguar Panthera onca on nesting beaches in TNP $\left(10^{\circ} 32^{\prime} 27^{\prime \prime} \mathrm{N}\right.$, $83^{\circ} 29^{\prime} 59^{\prime \prime} \mathrm{W}$ to $10^{\circ} 21^{\prime} 17^{\prime \prime} \mathrm{N}, 83^{\circ} 23^{\prime} 29^{\prime \prime} \mathrm{W}$ ). Including these cases, total necropsy data available for review included 19 immature turtles (straight carapace length [SCL] $\leq 60 \mathrm{~cm}$ ) and 3 sexually mature adults from Florida necropsied from 1997 to 2005, and kidneys from 47 adult nesting females from TNP necropsied from June to September of 2003 and 2004. Renal oxalosis was diagnosed when birefringent crystal deposition, consistent with calcium oxalate, was visible on standard paraffin-embedded, hematoxylin and eosinstained sections. Amounts of crystals observed in kidney sections were compared between cases and given a subjective score of relative abundance based on examination of all available sections. A 1-plus score was given for rare crystals, a 2-plus for small numbers of crystals, a 3-plus for moderate numbers and a 4-plus for large numbers (Fig. 1). Differences in the proportions of immature and mature turtles with renal oxalosis were tested for statistical significance.

Electron microscopy, X-ray and infrared analysis. Four representative cases (Cases 1, 7, 8, 9) were selected for analysis of the chemical composition of the birefringent crystals using a combination of infrared and scanning electron microscopy and energy dispersive X-ray analysis (Murakata et al. 2006). Briefly, 5 um thick sections were cut from paraffin-embedded formalin-fixed tissue and mounted on aluminum-coated glass slides for infrared analysis and on carbon stubs for scanning electron microscopy, samples were not coated. Infrared spectra were obtained by using a Nicolet Continuum infrared microscope $(32 \times$ reflective
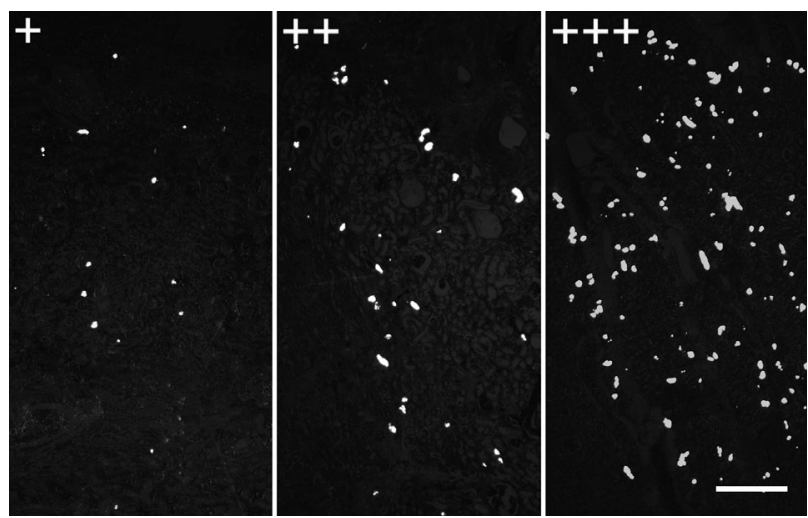

Fig. 1. Chelonia mydas. Calcium oxalate crystals in kidneys. Low magnification images viewed under polarized light demonstrate crystal numbers in kidneys from cases 12, 3 and 11 (left to right). Various numbers of birefringent crystals (white foci) are scattered throughout the sections; $(+,++,+++)$ relative quantities. Scale bar $=1 \mathrm{~mm}$ objective) attached to a Nicolet model 860 Fourier transform infrared (FT-IR) spectrometer (ThermoNicolet) equipped with a liquid nitrogen-cooled mercurycadmium-telluride (MCT) detector (ThermoNicolet). Sample spectra were adjusted based on background spectra obtained from blank regions on the aluminumcoated slide. Adjustable apertures (between 20 and $50 \mu \mathrm{m}$ ) were used to localize the infrared beam in the areas of interest. Spectra were recorded at $4 \mathrm{~cm}^{-1}$ spectral resolution, and 128 scans were co-added to reduce noise levels and provide adequate spectral quality. The measured infrared spectra were compared with those of authenticated samples and to spectra stored in a digital spectral library. The spectrometer was purged with dry air to minimize the effects of absorptions due to atmospheric water vapor and carbon dioxide.

A Hitachi model S-3500N scanning electron microscope equipped with a ThermoNoran energy-dispersive X-ray detection system was used for analyzing the elemental composition of the intracellular crystals. Samples were analyzed at an accelerating voltage of $15 \mathrm{kV}$ and a beam current of $25 \mu \mathrm{A}$. Carbon peaks were qualified by comparative analyses with samples mounted on aluminum stubs.

\section{RESULTS}

Green turtles with renal oxalosis included 6 turtles from Florida and 12 nesting females from TNP. Of the total number of green turtles from both locations for which histological sections of kidneys were available for review ( $\mathrm{n}=69), 28 \%(14 / 50)$ of adults and $21 \%$ (4/19) of immature turtles had renal oxalosis. There was no significant difference between the proportions of affected adult and immature turtles (1-tailed Fisher's exact test: $p=0.3983)$. Cases included 13 adult females, 1 adult male, 3 immature females and 1 immature male (Table 1). All but one (Case 4) were in good nutritional condition as assessed by adipose stores and muscle condition, and most animals died of acute traumatic events, predominantly predation (all turtles from TNP) or trauma (Cases 1, 2 \& 5). A single adult female from Florida (Case 3) suffocated following burial in a dune that collapsed on her while she was nesting. One immature female (Case 4) was euthanized due to inoperable fibropapillomatosis and an additional immature female (Case 6) died of fungal tracheitis. Gross changes in the kidneys only were detected in Case 1. In this animal, the medullary regions were diffusely white and firm on section. On histological examination, all cases had sheaves and rosettes of birefringent crystals present within tubular lumina that were associated with a granulomatous inflammatory response (Fig. 2). Crystals were primarily distributed throughout the cortical re- 
gion of all cases except Case 1. Crystal deposition in Case 1 was multifocally distributed within medullary regions. In all cases, the number of crystals ranged from small to moderate and density was patchy and variable within sections (Table 1, Fig. 1). No cases warranted a 4 -plus score. Crystals were often surrounded by granulomatous inflammation comprised of multinucleated giant cells and histiocytes bordered by various numbers

Table 1. Chelonia mydas. Details of necropsied individuals, geographic location and severity of crystal deposition (see Fig. 1 for examples of crystal number categories) in green sea turtles. Curved carapace length (CCL) taken from nuchal notch to posterior shell tip. All animals from Costa Rica are nesting females from Tortuguero National Park

\begin{tabular}{|c|c|c|c|c|c|}
\hline Case & Sex & Age class & $\mathrm{CCL}(\mathrm{cm})$ & Location & Crystals \\
\hline 1 & Female & Immature & 44.2 & St. Lucie County, FL & ++ \\
\hline 2 & Male & Adult & 102.9 & St. Lucie County, FL & ++ \\
\hline 3 & Female & Adult & 106.0 & Brevard County, FL & ++ \\
\hline 4 & Male & Immature & 38.1 & Indian River County, FL & + \\
\hline 5 & Female & Immature & 42.1 & Martin County, FL & +++ \\
\hline 6 & Female & Immature & 56.9 & Indian River County, FL & + \\
\hline 7 & Female & Adult & 106 & Costa Rica & +++ \\
\hline 8 & Female & Adult & 105 & Costa Rica & ++ \\
\hline 9 & Female & Adult & 101 & Costa Rica & ++ \\
\hline 10 & Female & Adult & 98 & Costa Rica & +++ \\
\hline 11 & Female & Adult & 111 & Costa Rica & +++ \\
\hline 12 & Female & Adult & 101 & Costa Rica & + \\
\hline 13 & Female & Adult & 98 & Costa Rica & ++ \\
\hline 14 & Female & Adult & 102 & Costa Rica & +++ \\
\hline 15 & Female & Adult & 98 & Costa Rica & ++ \\
\hline 16 & Female & Adult & 105 & Costa Rica & ++ \\
\hline 17 & Female & Adult & 92 & Costa Rica & + \\
\hline 18 & Female & Adult & 95 & Costa Rica & +++ \\
\hline
\end{tabular}

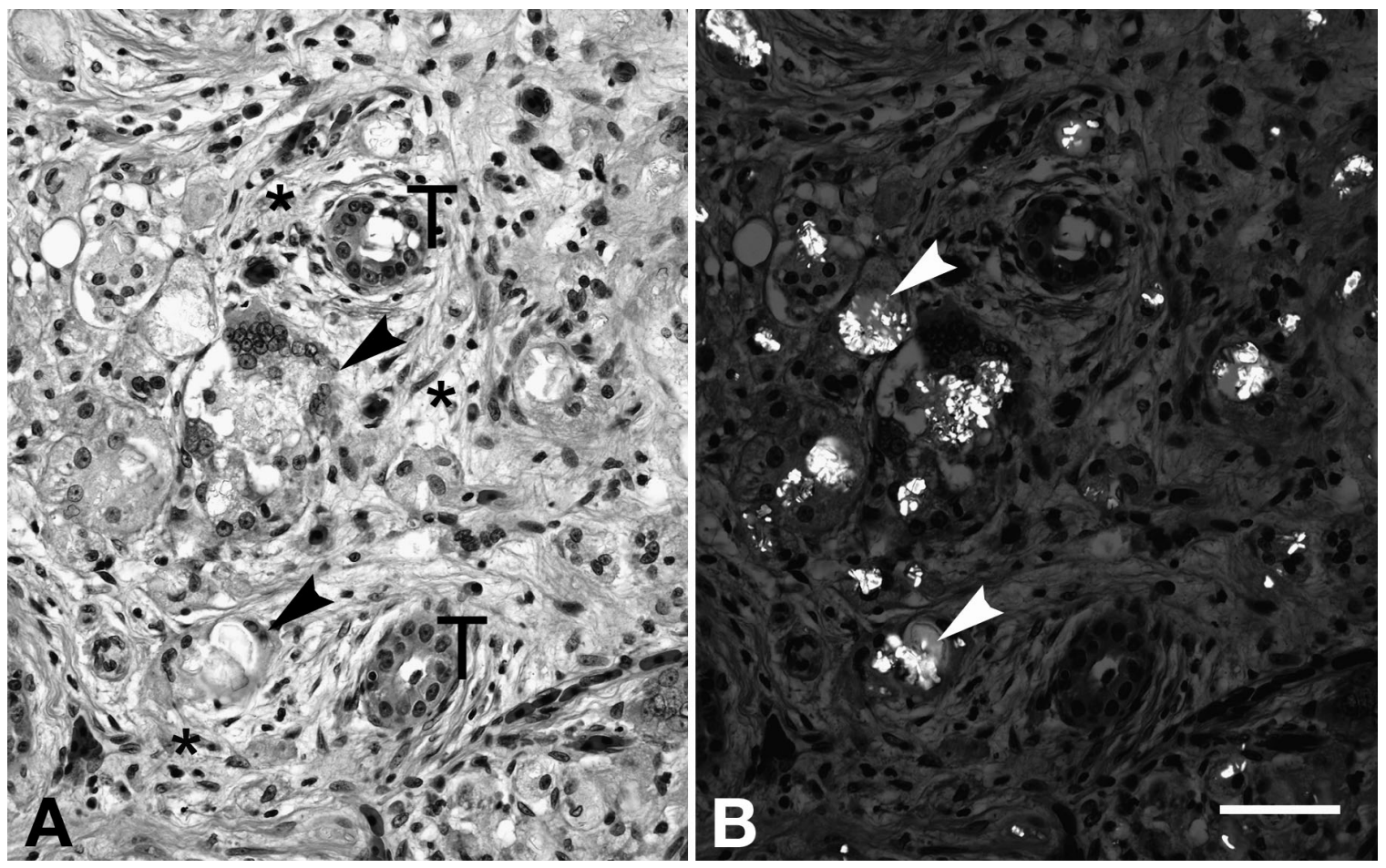

Fig. 2. Chelonia mydas. (A) Calcium oxalate crystals in the kidney (Case 1). Crystals fill the lumina of multiple damaged tubules and are surrounded by small granulomas with multinucleated giant cell formation (black arrowheads). Two intact tubules (T) are visible and the surrounding interstitium is expanded by fibrous connective tissue (*) and small numbers of migrating leukocytes.

(B) Crystals (white arrowheads) are more easily visualized under polarized light. Scale bar $=50 \mu \mathrm{m}$ 


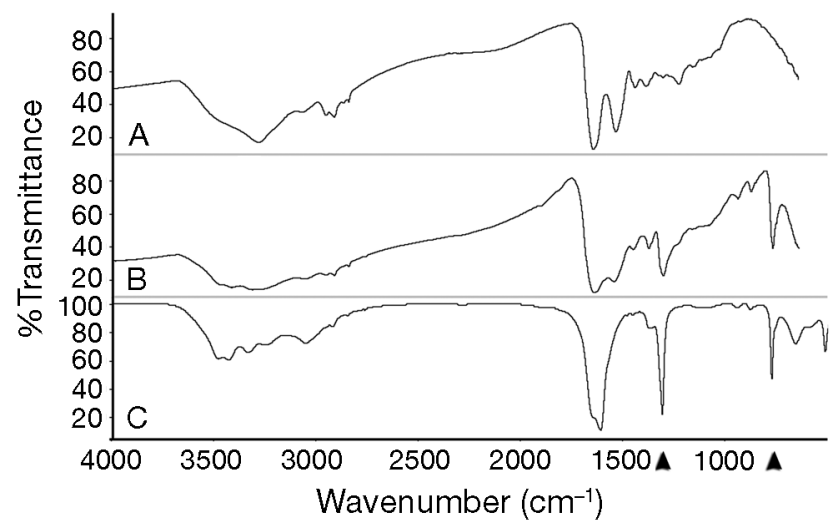

Fig. 3. Chelonia mydas. Infrared spectral analysis of (B) birefringent material within the kidney was compared to (A) adjacent renal tissue, and (C) an authenticated sample of calcium oxalate monohydrate. The most obvious features indicating calcium oxalate in (B) are the sharp reductions in transmittance at approximately 1320 and $780 \mathrm{~cm}^{-1}$ (black arrowheads), which are absent in the adjacent tissue

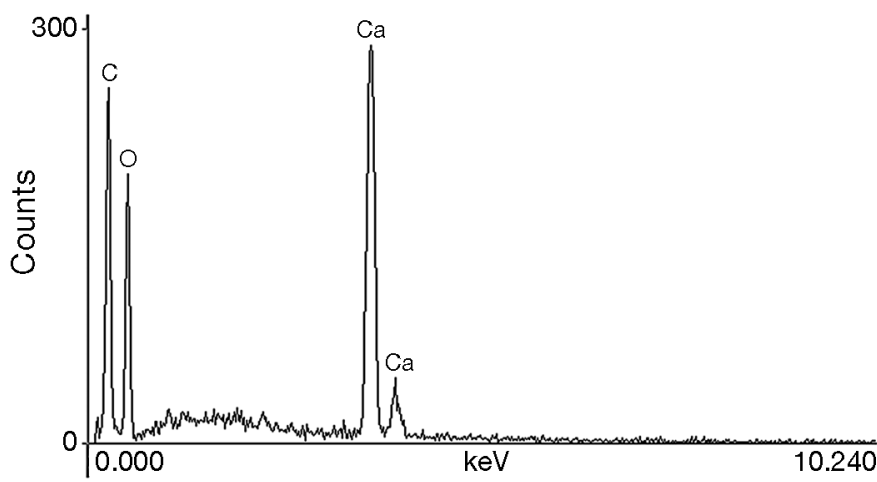

Fig. 4. Chelonia mydas. Spectra of the energy dispersive X-ray microanalyses of birefringent material within the kidney. The composite elements of calcium oxalate, which include calcium $(\mathrm{Ca})$, carbon $(\mathrm{C})$, and oxygen $(\mathrm{O})$, are detected within the crystals

of lymphocytes and heterophils. In most instances, affected tubules were completely effaced by crystals, inflammation and associated formation of fibrous connective tissue. Fibrosis was most extensive in Case 1 and prominently expanded the medullary regions. Epithelial cells in intact tubules containing crystals were often undergoing degeneration and necrosis, and tubular regeneration was observed in some cases. In addition, the kidneys of most mature turtles had focal to multifocally extensive areas of granulomatous inflammation, mixed granulocytic and lymphocytic inflammation and vasculitis associated with spirorchid trematode eggs.

The infrared spectra (Fig. 3) of the anisotropic crystalline material seen in kidneys of the 4 selected cases $(1,7,8$, and 9) exhibited all of the peaks associated with an authenticated sample of calcium oxalate monohydrate and differed from an adjacent area of kidney lacking this material. Additionally, data from energy dispersive X-ray microanalyses confirmed the crystals contained calcium, carbon and oxygen (Fig. 4). The crystalline morphology and the ancillary tests support identification of the crystals as calcium oxalate.

\section{DISCUSSION}

Based on the available necropsy data, renal oxalosis is a relatively common finding in green turtles inhabiting Florida waters and nesting in the TNP. Animals from the TNP may provide the best estimate of period prevalence, which was $25.5 \%$ in the study population. Obviously, the necropsy data is very biased towards nesting adult females. The proportion of affected adults was not significantly different from that of affected immature turtles, thus there was no evidence of age-related predisposition or oxalate crystal accumulation in the available study population.

Almost all animals were in good nutritional condition, most were nesting and/or actively feeding and had died from acute traumatic events or unrelated health problems, thus renal oxalosis was assessed to be incidental to the cause of death in all cases. Furthermore, crystals were relatively small in number and the overall extent of tubular injury was relatively minor. However, it is possible that crystal accumulation occurs in some animals and that associated chronic renal injury may become significant. One affected immature turtle (Case 1) had the most severe associated renal injury; therefore, it is arguable whether this animal would have survived to sexual maturity with normal renal function. Unfortunately, no blood chemistry values were available to assess renal parameters. Another interesting feature of this case was the distribution of the oxalate crystals, which where clustered within medullary regions. In contrast, all crystals in the adult and other immature turtles were cortical, as is observed with oxalate toxicosis in mammals. The medullary distribution in the immature turtle could reflect a different pathogenesis.

In domestic species, oxalate toxicosis is often caused by ingestion of ethylene glycol or oxalateaccumulating plants, such as Halogeton, Sarcobatus, Rumex, and Oxalis species (Maxie 1993). The latter usually occurs when animals are housed in areas with inadequate forage. Food materials contaminated by the oxalate-producing fungi Aspergillus niger and A. flavus are another common source. These circumstances are rare for free-ranging animals, thus there are very few published reports of oxalosis in wildlife. Ethylene glycol toxicosis has been reported in a released captive-bred California condor Gymnogyps 
californianus (Murnane et al. 1995) and was suspected in a free-ranging polar bear Ursus maritimus (Amstrup et al. 1989). Subclinical renal oxalosis was described in 12 of 59 wild-caught Japanese macaques Macaca fuscata (Yanai et al. 1995) and oxalate nephrosis was diagnosed in 4 of 235 free-ranging koalas Phascolarctos cinereus (Canfield 1989). In macaques, oxalosis was presumed to result from ingestion of oxalatecontaining plants.

Exposure of all of the green turtles in this study's 2 geographically distant groups to significant concentrations of synthetic toxicants, such as ethylene glycol, seems unlikely. As in other wild herbivores, renal oxalosis is more likely a result of consuming oxalatecontaining plants or other components of their diet. The diet of green turtles can vary by life stage and by region, but primarily includes either seagrasses or algae (Bjorndal 1997). All affected turtles from Florida with gastric contents had been feeding on macroalgae, whereas TNP nesting females primarily feed on seagrass (Bjorndal 1997). To date, no cases of renal oxalosis have been observed in carnivorous loggerhead turtles Caretta caretta which also strand in Florida and are subsequently necropsied at the University of Florida $(\mathrm{n}=70)$.

Oxalic acid or oxalate occurs in soluble and insoluble forms. Pathologic tissue deposition of oxalate and disease are associated with soluble forms, such as the metabolic formation of oxalic acid from ethylene glycol or the ingestion of soluble compounds, such as potassium oxalate (Maxie 1993). No major sources of soluble oxalate, such as that found in the aforementioned terrestrial plant species, have been identified in the marine environment. In contrast, insoluble oxalates, specifically calcium oxalate, function in calcium regulation and mechanical deterrence of herbivores (in terrestrial systems) and are found in a broad range of photosynthetic organisms, including seagrasses (Janauer 1981, Dobbs et al. 2004), algae (Franceschi \& Nakata 2005) and marine sponges (Cerrano et al. 1999). Some mammals may absorb low levels of calcium oxalate (Hanes et al. 1999); however, it is unknown whether consumption of insoluble oxalate results in pathologic tissue deposition under any circumstances, such as long-term ingestion. Oxalate absorption and metabolism in green turtles and the concentration of soluble and insoluble oxalates in seagrasses and other marine organisms relative to terrestrial species also are unknown.

The occurrence of renal oxalate deposition in over $20 \%$ of examined animals indicates that oxalosis is a common finding in Atlantic green turtles. Furthermore, it suggests that the source(s) of oxalate is encountered with some frequency. Renal oxalosis was regarded as incidental to the cause of death and most likely was subclinical in most, if not all cases reported in this study. Nevertheless, given the notable histopathological changes in the kidneys of an affected immature turtle and the potential for crystal accumulation, oxalosis may impair renal function in some animals and should be assessed during necropsy.

Acknowledgements. The authors thank Dr B. Homer for contributing archival necropsy materials and K. Singel, N. Brewer and E. Demaye for assistance with animal transportation. Also, we thank S. Fournies and the staff of Marinelife Center at Juno Beach for assistance with stranded animals. We are grateful to the Tortuguero Conservation Area park rangers for their logistical support and for facilitating field necropsies. Partial funding for this study was provided by the National Marine Fisheries Service. L.M.H. is a major in the US Army. The opinions and assertions contained herein are the private views of authors and are not to be construed as official or as reflecting the views of the Department of the Army or Department of Defense.

\section{LITERATURE CITED}

Amstrup SC, Gardner C, Myers KC, Oehme FW (1989) Ethylene glycol (antifreeze) poisoning in a free-ranging polar bear. Vet Hum Toxicol 31:317-319

Bjorndal KA (1997) Foraging ecology and nutrition of sea turtles. In: Lutz PL, Musick JA (eds) The biology of sea turtles. CRC Press, New York

Canfield PJ (1989) A survey of urinary tract disease in New South Wales koalas. Aust Vet J 66:103-106

> Cerrano C, Bavestrello G, Arillo A, Benatti U and others (1999) Calcium oxalate production in the marine sponge Chondrosia reniformis. Mar Ecol Prog Ser 179:297-300

> Dobbs FC, Zimmerman RC, Drake LA (2004) Occurrence of intracellular crystals in leaves of Thalassia testudinum. Aquat Bot 80:23-28

Franceschi VR, Nakata PA (2005) Calcium oxalate in plants: formation and function. Annu Rev Plant Biol 56:41-71

Hanes DA, Weaver CM, Heaney RP, Wastney M (1999) Absorption of calcium oxalate does not require dissociation in rats. J Nutr 129:170-173

Janauer GA (1981) Divergence in organic anion and amino compound concentrations in different parts of the leaves of Posidonia oceanica. Biochem Physiol Pflanz 174: 314-321

Maxie MG (1993) The urinary system. In: Jubb KVF, Kennedy PC, Palmer N (eds) Pathology of domestic animals. Academic Press, New York

Murakata LA, Lewin-Smith MR, Specht CS, Kalasinsky VF and others (2006) Characterization of acrylic polyamide plastic embolization particles in vitro and in human tissue sections by light microscopy, infrared microspectroscopy, and scanning electron microscopy with energy dispersive X-ray analysis. Mod Pathol 19:922-930

Murnane RD, Meerdink GL, Rideout BA, Anderson MP (1995) Ethylene glycol toxicosis in a captive-bred and released California condor (Gymnogyps californianus). J Zoo Wildl Med 26:306-310

> Yanai T, Wakabayashi S, Masegi T, Ishikawa K, Yamazoe K, Iwasaki $T$, Ueda $K$ (1995) Subclinical renal oxalosis in wild-caught Japanese macaques (Macaca fuscata). J Comp Pathol 112:127-131 